\title{
UMA ANÁLISE DA TRANSITIVIDADE VERBAL EM ORAÇÕES HIPOTÁTICAS ADVERBIAIS CAUSAIS SOB A PERSPECTIVA FUNCIONALISTA
}

\author{
Simone Maria Barbosa Nery NASCIMENTO \\ Universidade Estadual de Maringá \\ simoneuem@gmail.com
}

\begin{abstract}
Resumo: Este artigo é recorte de uma dissertação de mestrado. Nele, analisaram-se a transitividade e os planos discursivos (figura e fundo) na combinação entre orações hipotáticas adverbiais causais e suas respectivas orações-núcleo. A pesquisa fundamenta-se na proposta de Hopper e Thompson, Transitivity in grammar and discourse (1980), que utiliza 10 parâmetros sintático-semânticos que indicam o grau de transitividade de orações e possibilitam a identificação dos relevos discursivos figura e fundo. Verificou-se o funcionamento dos planos discursivos em combinações oracionais de elocuções formais. Para a coleta dos dados, foram realizadas gravações durante aulas de graduação e apresentações de trabalho, que, posteriormente, foram transcritas seguindo-se um padrão baseado nas normas do projeto NURC com algumas adaptações. Acredita-se que o gênero é determinante na seleção e para a recorrência de um determinado tipo de oração. No caso das elocuções formais, predominou a oração hipotática adverbial causal que se configurou como fundo para as suas orações-núcleo segundo os parâmetros da transitividade.
\end{abstract}

Palavras-chave: Transitividade. Planos discursivos. Hipotaxe adverbial causal.

Abstract: This article is a clipping of a dissertation. In it, we analyzed the transitivity and discursive plans (foregrounding and backgrounding) in the combination of hypotactic adverbial causal clauses and their main clauses. The research is based on Hopper \& Thompson's proposition, Transitivity in grammar and discourse (1980), which uses a taxonomy of 10 syntactic-semantic parameters which grade transitivity and help identify foregrounding and backgrounding in discourse. These 10 parameters will be tested on causal hypotactic clauses and on the main clauses with which they combine. To collect the data, recordings were made during some undergraduate classes and oral presentations, which were later transcribed following a pattern based on standards set by NURC project with some adjustments. It is believed that gender is a determining factor in the selection and to the recurrence of a particular kind of clause. In the case of formal utterances, the hypotactic causal adverbial clauses prevailed, which formed a background for the core sentences within the parameters of transitivity.

Keywords: Transitivity. Backgrounding and foregrounding in discourse. Causal adverbial hypotaxis. 


\section{Introdução}

Nas últimas décadas, algumas vertentes de estudos linguísticos têm direcionado suas investigações às manifestações do uso da língua. A gramática de base funcionalista verifica o uso das expressões linguísticas na interação verbal em suas diversas situações de uso e as estruturas linguísticas são analisadas sob o ponto de vista funcional. Nesse sentido, os estudos de uma língua natural baseados em abordagens funcionalistas têm como interesse examinar o modo como os usuários da língua se comunicam eficientemente, considerando as estruturas das expressões linguísticas como configurações de funções, sendo cada uma vista como um diferente modo de significação na oração.

Os funcionalistas norte-americanos Hopper e Thompson (1980) sugerem que, por meio da análise de 10 parâmetros sintático-semânticos, aplicados a orações, é possível identificar em narrativas algumas porções de texto que se sobressaem em relação a outras porções, estabelecendo os planos discursivos figura e fundo. Segundo Dik (1997), autores têm sugerido que as diferenças entre orações principais e subordinadas podem ser caracterizadas em termos de informação de primeiro plano (figura) e informação de segundo plano (fundo), ou informação asseverada versus informação pressuposta, o que significa que uma construção se correlacionaria com uma diferença na função pragmática. Neves (1999, p.461) também expõe que, para a construção causal, existe uma definição de que "é a que ressalta o fato de o segmento que expressa a causa ser uma pressuposição, e, portanto, constituir o fundo, ou seja, a parte recessiva do significado, e a parte 'causada' da construção ser dominante, isto é, ser a figura". Decat (2001) discute, ao tratar do papel funcional-discursivo da hipotaxe adverbial, se uma oração adverbial está constituindo realce, especificando, emoldurando a informação dada em outra porção de discurso pelo acréscimo de informações circunstanciais, ou, por outro lado, se ela tem função de conexão discursiva.

Para o estudo da transitividade e planos discursivos, o trabalho baseia-se nos procedimentos postulados por Hopper e Thompson (1980). Os autores 
afirmam que a transitividade é concebida como uma atividade escalar, contínua, não inerente ao verbo, mas manifestada na totalidade da oração.

\section{O Funcionalismo e a transitividade verbal conforme Hopper e Thompson (1980)}

Apesar das várias discussões na linguística a respeito do termo função, conforme afirma Halliday (1973), o termo se refere ao papel que a linguagem desempenha na vida dos indivíduos e não meramente aos papéis que as classes de palavras desempenham dentro da estrutura das unidades maiores.

A concepção funcionalista da linguagem pode ser sintetizada nas seguintes características: a linguagem é uma atividade sociocultural; a estrutura serve a funções cognitivas e comunicativas; a estrutura pode adaptarse aos propósitos comunicativos do falante, ela é maleável e não rígida; mudança e variação estão sempre presentes; o sentido é contextualmente dependente e não atômico; as categorias não são discretas; as gramáticas são emergentes; as regras de gramática permitem algumas exceções.

A proposta de análise da transitividade formulada por Hopper e Thompson (1980) é entendida como uma propriedade contínua, escalar, manifestada na totalidade da oração. Cunha et al. (2003, p.38-39) afirmam que a complexidade do conceito de transitividade reside no fato de que existem dez parâmetros sintático-semânticos (Quadro 01) que estão relacionados ao evento no qual um agente animado intencionalmente causa uma mudança física em um objeto. Isso significa que o contexto discursivo é fundamental na aferição da transitividade oracional. Os componentes da transitividade se caracterizam a partir dos parâmetros:

1) Participantes: Não há transferência a menos que dois participantes estejam envolvidos. 2) Cinese: Ações podem ser transferidas de um participante para outro, estados não. Dessa forma, em Eu abracei Sally, algo acontece com Sally, mas em Eu admiro Sally, nada acontece. 3) Aspecto: Uma ação vista do seu ponto final, isto é, uma ação télica (terminada), é mais efetivamente transferida para um paciente do que uma ação não terminada. $\mathrm{Na}$ oração télica Eu comi sanduíche, a atividade é vista como completa e a 
transferência é totalmente realizada; mas na oração atélica Eu estou comendo o sanduíche, a transferência é realizada apenas parcialmente. 4) Pontualidade: Ações realizadas sem nenhuma fase de transição óbvia entre o início e o fim têm um efeito mais marcado sobre seus pacientes do que ações que são inerentemente contínuas. Por exemplo: o verbo chutar é pontual em contraposição ao carregar, que é não pontual. Nesse caso, deve-se levar em conta o contexto e o significado do verbo. 5) Intencionalidade: $O$ efeito sobre o paciente é tipicamente mais aparente quando a ação do agente é apresentada como proposital. Por exemplo, Eu escrevi seu nome (intencional), em contraste com Eu esqueci seu nome (não intencional). 6) Polaridade: As orações afirmativas podem ser transferidas. Por exemplo: Eu entreguei o livro à professora. As negativas não podem pela falta de serem executadas. Por exemplo: O menino não comeu o sanduíche. 7) Modalidade: Refere-se à distinção entre a codificação "realis" e "irrealis" de eventos. Uma ação que não ocorreu, ou que é apresentada como tendo ocorrido em um mundo não-real, incerto, ou que expressa um evento hipotético, é obviamente menos efetiva do que aquela cuja ocorrência é de fato asseverada como correspondendo a um evento real. 8) Agentividade: Participantes que têm agentividade alta podem efetuar a transferência de uma ação de um modo que participantes com baixa agentividade não podem. Assim, a interpretação normal de George me assustou é de um evento perceptível com consequências perceptíveis, mas $O$ quadro me assustou poderia ser somente uma questão de estado interno. 0 quadro, no caso, é causativo. 9) Afetamento do Objeto: O grau em que uma ação é transferida para um paciente é uma função de quão completamente esse paciente é afetado. Assim, por exemplo, o afetamento é mais efetivo em Eu bebi o leite todo do que em Eu bebi um pouco do leite. 10) Individuação do Objeto: Esse componente se refere tanto ao fato de o paciente ser distinto do agente quanto à distinção entre o paciente e o fundo em que ele se encontra. Dessa forma, os referentes dos substantivos com propriedades de substantivo próprio, humano e animado, concreto, singular, contável e referencial ou definido são mais altamente individuados do que aqueles com substantivos que contêm propriedades contrárias às referidas acima. 
Cada um desses parâmetros contribui para a ordenação de orações em uma escala de transitividade. São mais transitivas as orações que possuem mais parâmetros da escala da alta transitividade (parâmetros marcados positivamente), e menos transitivas as orações com menos parâmetros da alta transitividade, conforme o quadro abaixo.

Quadro 1: Parâmetros para a análise da transitividade

\begin{tabular}{|l|l|l|}
\cline { 2 - 3 } \multicolumn{1}{c|}{} & \multicolumn{1}{c|}{$\begin{array}{c}\text { Transitivade Alta / } \\
\text { Parâmetros } \\
\text { positivos }\end{array}$} & $\begin{array}{c}\text { Transitividade } \\
\text { Baixa/ Parâmetros } \\
\text { negativos }\end{array}$ \\
\hline 2. Cinese & Dois ou mais & Um \\
\hline 3. Aspecto do verbo & Ação & Não ação \\
\hline 4. Pontualidade & Perfectivo (passado) & Não-perfectivo \\
\hline $\begin{array}{l}\text { 5. Intencionalidade do } \\
\text { sujeito }\end{array}$ & Pontual & Não-pontual \\
\hline $\begin{array}{l}\text { 6. Polaridade da oração } \\
\text { 7. Modalidade da oração }\end{array}$ & Afirmativa & Não-intencional \\
\hline 8. Agentividade do sujeito & Agentivo & Negativa \\
\hline 9. Afetamento do objeto & Afetado & Modo irrealis \\
\hline 10. Individuação do objeto & Individuado & Não-agentivo \\
\hline
\end{tabular}

(Cunha et al, 2003)

Segundo Hopper e Thompson (1980, p. 253), "uma ação pode ser mais efetivamente transferida para um paciente que é individuado do que para um que não é", portanto, um objeto definido é considerado como mais completamente afetado do que um objeto indefinido. Por exemplo: em Fritz bebeu a cerveja, existe uma possível ou provável implicação de que ele tomou toda a cerveja disponível, mas em Fritz bebeu um pouco da cerveja, não há essa implicação, a não ser que, na situação do evento, houvesse só a cerveja equivalente ao que bebeu. Da mesma forma acontece com pacientes animados e inanimados: em Eu me choquei com Charles, há, provavelmente, um foco de atenção no efeito do evento em Charles, ou talvez em ambos participantes, mas em Eu me choquei com a mesa, é menos provável que alguma coisa 
tenha acontecido com a mesa, e mais provável que o efeito sobre o agente esteja sendo ressaltado.

Cada um desses parâmetros contribui para a ordenação de orações em uma escala de transitividade. Embora independentes, funcionam articulados, determinando o grau de transitividade da oração. Vale ressaltar que orações tradicionalmente consideradas intransitivas, como Susan partiu, podem receber, nessa formulação, um grau de transitividade alto por possuir sete traços sintático-semânticos considerados positivos: cinese, aspecto perfectivo, verbo pontual, sujeito intencional, polaridade afirmativa, modalidade realis e sujeito agente (CUNHA e SOUZA, 2007).

Dessa forma, não apenas o verbo, mas toda a oração é classificada como mais ou menos transitiva, dependendo do número de traços marcados positivamente. Nessa perspectiva, a oração transitiva prototípica é a que, em um evento, possui um agente animado que intencionalmente causa uma mudança física e perceptível no estado ou na locação de um objeto. Cada uma dessas propriedades caracterizadoras da transitividade está relacionada ao relevo discursivo. Assim, por refletirem elementos cognitivamente importantes, os parâmetros da transitividade assinalam elementos relevantes no discurso. Hopper e Thompson (1980) consideram que há uma alta correlação entre o discurso e o grau de transitividade da sentença, uma vez que o maior ou o menor grau de transitividade é determinado pela maneira como o falante estrutura o seu discurso para atingir seus objetivos comunicativos e está de acordo com sua percepção das necessidades do ouvinte.

Como a transitividade oracional está relacionada à maneira como o falante organiza seu discurso, observa-se que um texto apresenta distinção entre o que é central e o que é periférico. Sendo assim, o grau de transitividade de uma oração reflete sua função discursiva. Apresentam uma alta transitividade as orações que assinalam a porção central ou dão sustentação ao texto - o que chamamos, em termos de planos discursivos, de figura enquanto a porção periférica ou com baixa transitividade corresponde ao fundo.

Em uma narrativa, a figura compreende o esqueleto do texto, faz o discurso progredir e apresenta a sequência temporal de eventos concluídos, 
pontuais, afirmativos, realis, sob a responsabilidade de um agente que constitui a comunicação central, enquanto a porção de fundo cobre essa estrutura básica sem fazer parte da coerência estrutural e sem contribuir para a progressão discursiva. O fundo corresponde à descrição de estados, da localização dos participantes da narrativa e à descrição de ações e eventos simultâneos ao plano da figura.

Conforme Pezatti (1994), em qualquer situação de fala, há uma parte do discurso mais relevante que a outra. Existem algumas características constitutivas dos planos discursivos na oração. As orações que constituem o plano figura fazem parte de uma linha principal de progressão do discurso; conservam o mesmo sujeito, introduzindo material novo no predicado; mantêm a continuidade tópica; mostram dinamicidade. Isso em contraste com as orações do plano de fundo que podem estar em qualquer lugar do discurso; contribuem para a montagem do cenário; dão suporte para o desenvolvimento discursivo; possibilitam mudança de tópico e introdução de informação nova, assim como alterações do sujeito; indicam situações descritivas/estáticas/imperfectivas; indicam estado ou situação para o entendimento de motivos e atitudes do falante.

Como a transitividade oracional está relacionada a uma função discursiva, Pezatti (1994) observa as tendências dessas propriedades sintático-semânticas associarem-se a tais planos discursivos. Segundo a autora, com relação ao traço participantes, há uma tendência para o fundo estar associado a um único argumento e figura a mais de um, tendo em vista que as partes do discurso que constituem o seu cenário tendem a se expressar por meio de formas verbais que denotam estados, sem que haja movimento de ação de um participante para outro.

Com relação ao traço cinese, observa-se que - ao contrário das orações de fundo, cujo verbo é não-cinético - as orações de figura narram eventos e indicam mudança de lugar ou condição.

Quanto ao aspecto, predicados télicos fazem parte da figura, uma vez que as orações recontam eventos que seguem uma ordem cronológica, sendo cada um visto em sua totalidade, do começo ao fim. No plano de fundo, os 
eventos são apresentados como repetidos ou simultâneos aos eventos de figura.

A pontualidade refere-se à ausência de uma clara fase transicional entre o início e sua completude. Verbos pontuais contrastam com os durativos, denotando eventos em figura.

Volitividade e agentividade referem-se ao grau de envolvimento do participante na atividade do verbo. Portanto, há uma maior incidência desses traços no plano de figura tendo em vista que os participantes envolvidos iniciam eventos e desempenham ações.

Modalidade e polaridade em eventos narrados implicam afirmação e acontecimentos reais, portanto, há uma raridade de orações negativas em figura.

Com relação à afetabilidade e individuação do objeto, a afetabilidade total decorre da perfectividade semântica do verbo, correlacionando-se ao plano de figura. A individuação corresponde a objetos definidos e objetos indefinidos são associados a estruturas intransitivas, o que sugere que tal argumento não constitui realmente um objeto, mas um acompanhamento adverbial do verbo.

Assim, no plano discursivo, a partir das dimensões figura e fundo, podem ser identificadas mais prontamente as entidades que se apresentam em primeiro plano como figuras bem recortadas e focalizadas, em oposição a tudo o mais, que passa a ser percebido contrastadamente como em plano de fundo.

\section{Análise e discussão dos dados}

De forma geral, pode-se dizer pela análise dos dados que as orações adverbiais causais, ao funcionarem como uma informação complementar, serviram de fundo no sentido de realçar, esclarecendo e reforçando a proeminência discursiva da oração-núcleo, e no sentido de justificar o tema enunciado na oração-núcleo, tida como figura.

Para a codificação dos dados e a constatação desses resultados, foram aplicados os dez parâmetros sintático-semânticos postulados por Hopper e 
Thompson (1980) para verificar qual das orações em relação é tida como fundo nas combinações analisadas.

No quadro a seguir, apresentam-se os resultados da aplicação dos traços da transitividade nas orações-núcleo e nas adverbiais causais. Por meio dos dados quantificados, com relação aos parâmetros positivos e negativos, observa-se que o gênero estudado, elocução formal, em geral, possui baixa transitividade. Acredita-se que isso aconteça pela escolha que se faz dos verbos de não ação e os seus traços semânticos, como o aspecto verbal, pontualidade, além da agentividade e intencionalidade do sujeito marcados negativamente. Isso reforça a ideia de que os traços estão estritamente ligados e são dependentes uns dos outros. Os traços aspecto verbal e pontualidade do verbo, conforme o quadro abaixo, tiveram uma alta frequência marcada negativamente. Por meio desses resultados, pôde-se notar a não-dinamicidade do gênero e do tipo de combinação oracional, nos quais prevaleceram os verbos sem focalização temporal, o contrário de uma narrativa com sucessivos eventos.

A primeira coluna refere-se aos traços encontrados nas orações-núcleo e a segunda coluna, aos traços das orações adverbiais causais.

Quadro 02: Valores da transitividade para as orações-núcleo e as orações causais

\begin{tabular}{|l|c|c|c|c|}
\hline \multicolumn{1}{|c|}{ PARÂMETROS } & \multicolumn{2}{c|}{ OR. NÚCLEO } & \multicolumn{2}{c|}{ OR. CAUSAL } \\
\hline PARTICIPANTES & $\%$ & $\mathrm{~N}$ & $\%$ & $\mathrm{~N}$ \\
\hline dois ou mais & & & & \\
\hline um & $57,4 \%$ & 74 & $22,3 \%$ & 29 \\
\hline AFETAMENTO DO OBJETO & $42,6 \%$ & 55 & $77,7 \%$ & 101 \\
\hline afetado & & & & \\
\hline não-afetado & $10,9 \%$ & 14 & $4,6 \%$ & 6 \\
\hline INDIVIDUAÇÃO DO OBJETO & $46,5 \%$ & 60 & $17,7 \%$ & 23 \\
\hline individuado & & & & \\
\hline não-individuado & $3,1 \%$ & 4 & $1,5 \%$ & 2 \\
\hline
\end{tabular}




\begin{tabular}{|c|c|c|c|c|}
\hline CINESE & & & & \\
\hline Ação & $57,4 \%$ & 74 & $25,4 \%$ & 33 \\
\hline Processo & $6,2 \%$ & 8 & $7,7 \%$ & 10 \\
\hline ação-processo & $0,8 \%$ & 1 & $0,0 \%$ & 0 \\
\hline Estado & $35,7 \%$ & 46 & $66,9 \%$ & 87 \\
\hline AGENTIVIDADI & & & & \\
\hline Agentivo & $24,0 \%$ & 31 & $6,9 \%$ & 9 \\
\hline não-agentivo & $33,3 \%$ & 43 & $18,5 \%$ & 24 \\
\hline ASPECTO VER & & & & \\
\hline perfectivo & $12,4 \%$ & 16 & $12,0 \%$ & 15 \\
\hline não-perfectivo & $87,6 \%$ & 113 & $88,0 \%$ & 115 \\
\hline PONTUALIDAD & & & & \\
\hline pontual & $19,4 \%$ & 25 & $6,9 \%$ & 9 \\
\hline não-pontual & $80,6 \%$ & 104 & $93,1 \%$ & 121 \\
\hline $\begin{array}{l}\text { INTENCIONALI } \\
\text { SUJEITO }\end{array}$ & & & & \\
\hline intencional & $34,9 \%$ & 45 & $16,2 \%$ & 21 \\
\hline não-intencional & $65,1 \%$ & 84 & $83,8 \%$ & 109 \\
\hline POLARIDADE & & & & \\
\hline Afirmativa & $87,6 \%$ & 113 & $79,2 \%$ & 103 \\
\hline Negativa & $12,4 \%$ & 16 & $20,8 \%$ & 27 \\
\hline MODALIDADE & & & & \\
\hline Realis & $71,3 \%$ & 92 & $77,7 \%$ & 101 \\
\hline Irrealis & $28,7 \%$ & 37 & $22,3 \%$ & 29 \\
\hline
\end{tabular}

Obs. Para os verbos de não-ação, a agentividade do sujeito não foi marcada.

Em um balanço geral de todo o corpus, os dados revelam que há a predominância de ocorrências de traços da baixa transitividade. Mesmo levando em consideração a grande quantidade de ocorrências de traços marcados positivamente, os da polaridade e modalidade da oração - somados em 409 em contraste com as ocorrências de parâmetros negativos, somados em 109 - observa-se uma diferença de 645 ocorrências a mais da baixa transitividade. Acredita-se que isso se deve à natureza do gênero em estudo, ao selecionar, por exemplo, verbos estativos e durativos com perfectividade e 
pontualidade negativas, traços estes, como visto, com maiores frequências de ocorrências no gênero.

No Brasil, estudos da transitividade sob essa ótica norte-americana (SILVEIRA, 1990; CUNHA et al, 2003; CUNHA e SOUZA, 2007) têm demonstrado grande contribuição em estudos narrativos. Aplicam-se os parâmetros e obtêm-se os planos discursivos figura e fundo. Presume-se que, nesse gênero, seja comum haver o relato de uma história com personagens agindo em um determinado local e época. Portanto, é comum encontrarem-se ações efetivas em tal gênero e consequentemente orações altamente transitivas, ou seja, orações de figura sobrepostas às porções de fundo.

No entanto, como visto, Cunha et al. (2003) testam a possibilidade de aplicação dos parâmetros da transitividade a outros gêneros textuais não narrativos. Mostram que um gênero textual pode servir de fundo a outro gênero ou um trecho narrativo pode servir de fundo em um trecho maior não narrativo.

Desse modo, comparou-se a frequência geral dos parâmetros nas orações causais e nas orações-núcleo em elocuções formais e verificou-se um maior índice de ocorrências de parâmetros positivos nas orações-núcleo, com 488 versus 328 nas adverbiais causais. Quanto aos parâmetros negativos, houve 692 ocorrências de parâmetros negativos nas orações-núcleo e 770 nas adverbiais causais. A frequência de traços negativos nas orações-núcleo se justifica, em grande parte, conforme o quadro, pelos traços aspecto verbal e pontualidade verbal, comuns em tal gênero textual.

Segundo Cunha e Souza (2007), cada um dos parâmetros envolve uma faceta diferente da eficácia ou da intensidade com que a ação é transferida de um participante a outro. No sentido de explanar os parâmetros sintáticosemânticos, será apresentada, com exemplos do corpus, uma exemplificação do funcionamento de cada um deles em situações reais de fala do corpus.

\subsection{Números de participantes}

Quanto ao parâmetro participantes (número de participantes no evento), verifica-se a sua alta frequência nas orações-núcleo. Vale ressaltar a 
relevância de se marcar ou não esse traço, que dele dependem outros dois traços: afetamento do objeto e individuação do objeto, aumentando o grau da transitividade, quando presentes. Sabe-se que, na gramática tradicional, para que um verbo seja transitivo, a presença do objeto é obrigatória. Para Hopper e Thompson (1980), portanto, para que uma oração seja transitiva, o objeto não é uma exigência absoluta, no entanto, possibilita a transferência e aumenta o grau de transitividade. Seguem os exemplos:

(07).. aí .. você vai fazer todas as contas que forem possíveis...(A3)

(08).. só mudei os números. (A1)

(09)..então como nós escolhemos .. a região do litoral carioca .. e do nordeste. (AT4)

Nos casos acima, existem os sujeitos e os objetos, ou seja, mais de um participante em cada oração. No entanto, apesar de o número de participantes contribuir para o alto grau de transitividade nas orações, não significa que tenha ocorrido a transferência de um participante a outro. Na oração (07), por exemplo, que faz parte de uma aula de matemática em um curso de engenharia, a modalidade marcada negativamente (evento hipotético, tempo futuro) não permitiu a construção do objeto “todas as contas" pelo sujeito "você". Assim, percebe-se a dependência existente entre os traços da transitividade.

O contrário pode acontecer com orações que possuem apenas um participante, como a seguir, em destaque:

(10) já abaixou aquela ansiedade do primeiro experimento.. né.(A1)

Tradicionalmente, essa oração seria considerada intransitiva, mas, sob a perspectiva funcionalista norte-americana, ela pode assinalar traços da alta transitividade. No contexto do exemplo, o professor orienta os alunos para que cheguem no horário da próxima aula a fim de irem direto ao experimento que realizarão. Esse evento pode ser realizado por terem os alunos já passado pela experiência do experimento, conforme a afirmação no exemplo (10). Ao analisá-la, percebe-se que existe um evento no mundo real. Isso significa que já foram marcados ao menos dois parâmetros positivos, o da modalidade e o 
da polaridade. Outro traço identificado foi o aspecto perfectivo. Portanto, apesar de possuir apenas 01 participante ("aquela ansiedade do primeiro experimento"), houve um evento concluído, ou seja, existe transitividade na oração.

Como visto, dependem do parâmetro participantes os traços afetamento e individuação do objeto, ou seja, havendo mais de um participante na oração, este pode ser, de alguma forma, afetado ou não, individuado ou nãoindividuado.

\subsection{Afetamento e individuação do objeto}

Havendo mais de um participante na oração, analisam-se a sua individuação e o seu afetamento. Para Hopper e Thompson (1980), o grau em que uma ação é transferida para um paciente é uma função de quão completamente esse paciente é afetado. No exemplo (08), o objeto "os números" não foi simplesmente afetado, mas construído no momento da elaboração de uma suposta equação matemática. No exemplo (09), o objeto ".. a região do litoral carioca .. e do nordeste" não sofreu qualquer mudança em seu estado físico. Quanto à individuação do objeto, além das propriedades relativas ao paciente e ao fundo em que ele se encontra, os autores alegam que o paciente deve ser distinto do agente. No exemplo (07), citado acima, não se pode dizer que "todas as contas" é um objeto individuado, pois, apesar de ser o paciente diferente do sujeito agente, é um objeto comum, inanimado, plural e incontável. Segue o exemplo de um objeto considerado individuado:

(11)...porque tem que ver o texto primeiro da prática que vocês já viram, (A1)

Nesse caso, o professor orienta sobre um relatório que os alunos deverão realizar. Para tanto, deverão ler o texto sugerido, conforme o exemplo. O objeto da oração, "o texto", além de ser concreto, singular, contável e definido, é distinto do sujeito do evento. 


\subsection{Cinese}

Outro dado relevante apresentado na análise com uma considerável disparidade entre os tipos de oração foi com relação à tipologia verbal. Desse modo, o falante, ao selecionar verbos de ação, está propondo uma maior visualização mental do evento para o seu interlocutor, isto é, o relevo discursivo é exposto de forma mais aparente. A diferença entre os dois tipos verbais pode ser observada nos seguintes exemplos com os verbos em destaque:

(12) .. a gente embute aí um resultado, (A1)

(13) .. porque ele ia ficar .. CONVENCIDO .. né::. (A3)

O exemplo (12) se refere a um relatório solicitado aos alunos que não tem o item discussão para explicar os resultados do trabalho, portanto, o professor sugere que, inicialmente, apenas apresentem o resultado. No exemplo (13), o professor comenta a escrita de um aluno em uma avaliação, alega que não queria falar para o aluno não ficar convencido. No evento do exemplo (12), além de haver um verbo de ação, este ainda possibilita a agentividade e a intencionalidade do sujeito da oração, além de outros traços marcados positivamente. Os verbos de ação geralmente aparentam selecionar, mais do que os verbos de estado, dois participantes para um evento, conforme no exemplo (12), em que existe um sujeito "a gente" que age sobre ou constrói um paciente "um resultado". Os verbos de estado, ao contrário, não se relacionam com o seu complemento da mesma forma que os verbos de ação, ou seja, enquanto em (12) é possível a visualização do evento, ou de uma passagem de um participante para o outro, no exemplo (13), o complemento oracional não é concreto, é um atributo do sujeito, um estado interno do sujeito. Dessa forma, considerando a análise semântica da oração, não há como visualizar qualquer transferência. Semelhantemente, alguns verbos como "ter", segundo Cunha e Souza (2007), ocorrem em arranjos sintáticos nitidamente transitivos, como em "ela tinha o cabelo lindo." No entanto, não existe uma transferência. Acredita-se que o número de participantes e a tipologia verbal sejam marcados 
negativamente nas orações causais por sua natureza explicativa, que, para tanto, necessita selecionar alguns tipos de verbos estativos.

\subsection{Agentividade do sujeito}

Quanto à agentividade do sujeito, pode-se observar, no exemplo a seguir, como os participantes que têm agentividade alta podem efetuar transferência:

(14) .. e aqui eu coloquei dispersões coloiDAis. (A2)

No evento, o sujeito "eu" pratica uma ação que exige um deslocamento tanto da pessoa que age quanto do objeto afetado. O objeto "dispersões coloidais" é um componente químico utilizado em uma aula do curso de farmácia, portanto, é um objeto concreto. Assim, a interpretação que se tem nessa oração é de um evento com consequências perceptíveis.

\subsection{Aspectos verbais}

Neves (1999), em estudo sobre as orações causais, verificou sobre o aspecto verbal que, dentre os tipos de predicação com relações causais, combinações que envolvem orações estativas são a maioria, predicações estas marcadas pela ausência de telicidade em 86,0\% das ocorrências. Percebe-se, pelos dados, a relação existente entre a tipologia verbal e os parâmetros que indicam duração. As predicações de estado analisadas por Neves (1999) estão em $38,0 \%$ das orações-núcleo e em $53 \%$ das orações causais. Verificou ainda que as predicações de estado estão em cerca de $70 \%$ das construções causais examinadas.

Com relação ao aspecto verbal, este trabalho também revela uma maior frequência de orações imperfectivas. Segundo Hopper e Thompson (1980), uma ação télica é mais eficazmente transferida para um participante do que uma ação que não tenha término. Os exemplos a seguir mostram a diferença entre os aspectos perfectivo e imperfectivo: 
(15).. ah eu COPIEI DO OUTRO. (A1)

(16).. porque.. né .. acento é uma coisa que desconhe.::ce.. né (A3)

No exemplo (15), existe uma ação télica, perfectiva, quando o professor repete a fala do aluno que copiou o trabalho do outro, refazendo e melhorando o seu, enquanto no exemplo (16) percebe-se certa atemporalidade. Nesse caso, o professor comenta os erros ortográficos corrigidos por ele no trabalho. Acredita-se que o aspecto imperfectivo dos verbos encontrado no corpus se justifica pela natureza durativa ou permanente com função de, geralmente, caracterizar algo, como no exemplo (16). Na análise de Neves (1999), também há uma grande frequência desse tipo de verbo no tempo presente do indicativo.

\subsection{Pontualidade verbal}

A pontualidade do verbo é outro aspecto que se acredita depender, em parte, da tipologia verbal, pois os verbos estativos geralmente têm, em sua natureza, a durabilidade. Isso não significa que os verbos de ação não possam ser durativos, ou seja, verbos de ação como carregar e discorrer têm em seu lexema um valor durativo. Segundo Hopper e Thompson (1980), ações realizadas sem nenhuma fase de transição óbvia entre o início e o fim têm um efeito mais marcado sobre os pacientes do que ações que são inerentemente contínuas. Seguem os exemplos com o contraste entre duas orações em que (17) é pontual, pois se trata de um relatório solicitado pelo professor, e (18) é não pontual.

(17) .. ele não refaz.

.. ele me entrega daquele jeito mesmo .. tá.

.. eu não sei se.: .. porque ele tem muita coisa pra fazer,

.. ele larga pra lá::.. né,

.. aí ele não se interessa muito por refazer. (A1)

(18) .. língua e variação da fala são inseparáveis, (AT4) 
2.7 Intencionalidade do sujeito

Os exemplos (17) e (18) acima podem ser utilizados para se verificar a intencionalidade do sujeito da ação. Percebe-se que, no exemplo (17), o efeito de largar algo é proposital, o que não acontece no exemplo (18). Esses dados contribuem para a baixa transitividade das orações adverbiais em questão.

\subsection{Modalidade e polaridade da oração}

Com relação aos parâmetros modalidade e polaridade da oração, esses dizem respeito à realização ou não do evento, o que não significa que uma oração negativa tenha a modalidade também negativa. No caso da modalidade, um evento hipotético ou que é apresentado em um mundo nãoreal é menos eficaz, segundo Hopper e Thompson (1980), do que uma ação cuja ocorrência corresponde a um evento real. O exemplo (19) a seguir é um modelo de oração afirmativa e o exemplo (20) é de oração negativa. Nos exemplos, o professor comenta as atitudes de alguns alunos com relação à prova.

(19) .. porque ele estudou pela metade .. né, (A3)

(20) .. porque .. né .. algumas pesso::as .. não estudaram pra fazer a prova. (A3)

Os exemplos a seguir servem para explicitação da modalidade:

(21) .. porque muitos auto::res .. ele::s classificam as soluções coloiDAis como dispersões grosseiras (A2)

(22) .. então preste atenção.. né, (A3)

(23) .. porque ela pode ser mais de uma vez .. né .. né:: (A3)

Enquanto no exemplo (21) é nítida a realização do evento, nos exemplos (22) e (23), retirados de uma aula de matemática em que o professor comenta os exercícios resolvidos pelos alunos, não se pode dizer o mesmo. Na ocorrência (22), o verbo está no modo imperativo, ou seja, é uma ordem que poderá ou não ser atendida, e, no exemplo (23), existe uma hipótese, possibilidade que também pode não ser verdade. 
Por meio da exemplificação dos parâmetros, verifica-se o modo como a transitividade foi analisada para se chegar aos relevos discursivos das orações. Pôde-se constatar, além da dependência existente entre os traços, que os parâmetros indicam o grau de realização de uma ação ou de um evento, ou se o evento é real ou hipotético. Nesse sentido, como forma de construção e organização do discurso, a análise da transitividade nos permite evidenciar as crenças, esperanças, intenções, afirmações sobre o conhecimento do falante e descrições e acontecimentos sobre o que está a sua volta. No caso da elocução formal, pôde-se notar que o falante organiza o seu enunciado conforme o conhecimento que tem acerca de certo conteúdo. Por serem apresentações de trabalhos e aulas, portanto, a transmissão de alguns conhecimentos e os enunciados produzidos nas elocuções formais, geralmente, são afirmações rígidas a respeito de tal conteúdo, Nesse sentido, são utilizados os verbos estativos, como ser e estar, por exemplo.

\section{Conclusão}

O presente trabalho, com o objetivo de detectar os planos discursivos em orações hipotáticas adverbiais causais e suas orações-núcleo, realizou uma análise baseada na transitividade fundamentada em Hopper e Thompson (1980). Para tal análise, utilizou-se um corpus composto de 10 elocuções formais em que foram participantes professores e alunos universitários de Maringá (PR).

A hipótese inicial de que as orações hipotáticas causais, por sua natureza descritiva, de realçar ou de emoldurar situações, pudessem funcionar como fundo para as orações-núcleo se confirmou. Constatou-se pela análise dos dados, que, ao selecionarem verbos estativos, que auxiliavam na exposição do conteúdo ministrado em aulas e apresentações de trabalho (elocuções formais), as orações causais codificaram menos parâmetros da escala da alta transitividade do que as suas orações-núcleo que, por sua vez, tiveram um maior grau de transitividade por frequentemente selecionarem verbos de ação. Nesse sentido, portanto, as orações causais funcionaram como fundo para as 
orações-núcleo. Por se tratarem de aulas e exposições de trabalhos, em que está em jogo a compreensão do interlocutor, percebeu-se que os falantes das elocuções formais utilizaram as orações adverbiais causais como recurso linguístico para a explicitação do conteúdo, no sentido de explicar, de detalhar, enfatizar ou até mesmo reforçar a ideia do que foi exposto na oração-núcleo.

Como exemplificação da aplicação dos parâmetros, procedeu-se uma análise de cada um deles. Pôde-se constatar, assim, a dependência existente entre os traços, o grau de realização de um evento e se o evento é real ou hipotético. Por esses resultados, ainda, obteve-se o relevo discursivo das orações.

Conclui-se, portanto, que as pressões de ordem pragmática recaem sobre a estrutura da língua, o que pôde ser explicado pelos dados que demonstram que o falante, tanto para justificar seus argumentos, como para salientar uma informação, utiliza-se do mesmo recurso, que são as orações hipotáticas causais, no entanto, somente as organiza de formas diferentes.

\section{Referências bibliográficas}

CUNHA, M.A.F. et al. Lingüística funcional: teoria e prática. Rio de Janeiro: DP\&A, 2003.

CUNHA, M.A.F; SOUZA, M.M. Transitividade e seus contextos de uso. Rio de Janeiro: Lucerna, 2007.

CUNHA, C.; CINTRA, L.F.L. Nova gramática do português contemporâneo.

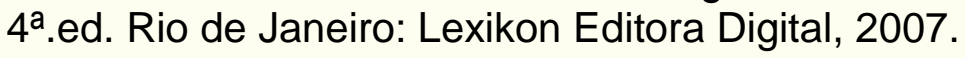

DECAT, M.B.N. Aspectos da gramática do português: uma abordagem funcionalista. Campinas/SP: Mercado de Letras, 2001.

DIK, C.S. The theory of Functional Grammar. Dorderecht-Holland/Providence RI-EUA: Foris Publications, 1989.

1997.

. The theory of functional grammar. New York: Mouton de Gruyter,

HALLIDAY, M.A.K. Explorations in the Functions of Language. Londres: Edward Arnold, 1973. 
Publishers, 1985.

An introduction to functional grammar. London: Edward Arnold

HOPPER, P.; THOMPSON S. Transitivity in grammar and discourse. Language, Washington, v.56, n.2, p.252-299, 1980.

NEVES, M. H. M. A Gramática Funcional. S. Paulo: Martins Fontes, 1997.

. (org.) Gramática do português falado. V. 7. São Paulo: Humanitas/FFLCH/USP, Campinas: Editora da Unicamp. 1999.

. Gramática de usos do português. São Paulo: Editora UNESP, 2000.

. (org.). Descrição do Português: definindo rumos de pesquisa.

Laboratório Editorial UNESP. São Paulo: Cultura Acadêmica Editora, 2001.

PEZATTI, E.G. Uma abordagem funcionalista da ordem de palavras no português falado. Alfa, São Paulo, 1994, p. 37-56

. O funcionalismo em linguística. In: MUSSALIM, F.; BENTES, A.C.

(org.) Introdução à lingüística: fundamentos epistemológicos. São Paulo: Cortez, 2004.

Artigo recebido em: 15 de abril de 2013

Artigo avaliado em: 30 de maio de 2013

\section{Sobre a autora:}

Doutoranda em Letras/Linguística Aplicada no programa de Pós-graduação em Letras - PLE/Universidade Estadual de Maringá (UEM). 